\title{
LIV. Experimental researches in electricity.-Fifteenth series
}

\section{Michael Faraday Esq. D.C.L. F.R.S.}

To cite this article: Michael Faraday Esq. D.C.L. F.R.S. (1839) LIV. Experimental researches in electricity.-Fifteenth series, Philosophical Magazine, 15:97, 358-372, DOI: 10.1080/14786443908649901

To link to this article: http://dx.doi.org/10.1080/14786443908649901

册 Published online: 01 Jun 2009.

Submit your article to this journal $\pi$

Џll Article views: 7

Q View related articles $\asymp$

Citing articles: 1 View citing articles 
358 Dr. Faraday's Experimental Researches in Electricity, xv.

tions, that " if any hexagon be circumscribed about any conic section, and the opposite angles be joined, the three diagonals have a common intersection." I believe mine was the first attempt to prove this very curious proposition algebraically, but a simpler demonstration of that theorem has since been given by an anonymous writer in the Cambridge Mathematical Journal, and it follows from the method there adopted that the property which I had noticed for the parabola,

$$
y_{1}-y_{2}+y_{3}-y_{4}+y_{5}-y_{6}=0
$$

may be extended to any polygon of an even number of sides circumscribing a parabola, so that

$$
y_{1}-y_{2}+y_{3}-y_{4} \quad \cdots \cdots \cdots+y_{2 n-1}-y_{2 n}=0 \text { 。 }
$$

LIV. Experimental Researches in Electricity. - Fifteenth Series. By Michael Faraday, Esq., D.C.L., F.R.S., Fullerian Prof. Chem. Royal Institution, Corr. Memb. Royal and Imp. Acad. of Sciences, Paris, Petersburgh, Florence, Copenhagen, Berlin, Gottingen, Modena, Stockholm, \&c. \&c.*

$\$ 23$. Notice of the character and direction of the electric force of the Gymnotus.

174.9. WONDERFUL as are the laws and phænomena of electricity when made evident to us in inorganic or dead matter, their interest can bear scarcely any comparison with that which attaches to the same force when connected with the nervous system and with life; and though the obscurity which for the present surrounds the subject may for the time also veil its importance, every advance in our knowledge of this mighty power in relation to inert things, helps to dissipate that obscurity, and to set forth more prominently the surpassing interest of this very high branch of Physical philosophy. We are indeed but upon the threshold of what we may, without presumption, believe man is permitted to know of this matter; and the many eminent philosophers who have assisted in making this subject known, have, as is very evident in their writings, felt up to the latest moment that such is the case.

1750. The existence of animals able to give the same concussion to the living system as the electrical macbine, the voltaic battery, and the thunder storm, being with their habits marle known to us by Richer, S'Gravesende, Firmin, Walsh, Humboldt, \&c. \&c., it became of growing importance to identify the living power which they possess, with that which man can call into action from inert matter, and by him named electricity $(265,351$.$) . With the Torpedo this has been done$ to perfection, and the direction of the current of force deter-

* From the Philosophical Transactions for 1839, Part I. p. 1. 
mined by the united and successive labours of Walsh*, Cavendish $\dagger$, Galvani†, Gardini $\oint$, Humboldt and Gay-Lussac \|, Todd $\uparrow$, Sir Humphry Davy**, Dr.Davy†t, Becquerel 拉, and Matteucci $\oint \delta$.

17.51. TheGymnotus has also been experimented with for the same purpose, and the investigations of Williamson \|\| , Gar$\operatorname{den} \Upsilon$ T, Humboldt $* * *$, Fahlberg $\dagger+\dagger$ and Guisan $\ddagger \ddagger$, have gone very far in showing the identity of the electric force in this animal with the electricity excited by ordinary means; and the two latter philosophers have even obtained the spark.

1752. As an animal fitted for the further investigation of this refined branch of science, the Gymnotus seems, in certain respects, better adapted than the Torpedo, especially (as Humboldt has remarked) in its power of bearing confinement, and capability of being preserved alive and in health for a long period. A Gymnotus has been kept for several months in activity, whereas Dr. Davy could not preserve Torpedos above twelve or fifteen days; and Matteucci was not able out of 116 such fish to keep one living above three days, though every circumstance favourable to their preservation was attended to \|\|$\|$. To obtain Gymnoti has therefore been a matter of consequence; and being stimulated, as much as $I$ was honoured, by very kind communications from Baron Humboldt, $I$ in the year 1835 applied to the Colonial Office, where I was promised every assistance in procuring some of these fishes, and continually expect to receive either news of them or the animals themselves.

1753. Since that time Sir Everard Home has also moved a friend to send some Gymnoti over, which are to be consigned to His Royal Highness our late President; and other gentlemen are also engaged in the same work. This spirit induces me to insert in the present communication that part of the letter from Baron Humboldt which $I$ received as an answer to my inquiry of how they were best to be conveyed across the Atlantic. He says, "The Gymnotus, which is

* Philosophical Transactions, 1773, p. 461. † Jbid. 1776, p. 196.

‡ Aldini's Essai sur le Galvanisme, ii. 61.

De Electrici Ignis Natura, \$. 71. Mantua, 1792.

II Annales de Chimie, xiv. 15.

Phil. Mag., First Series, vol, xlviii. p. 14.]

Phil. Mag. and Annals, vol. vi. p. 81.] H. HIbid. 1832, p. 259; and
1834, p. 531. [see Lond, and Edinb. Phil. Mag., vol. i. p. 67; xi. p. 57.]

$\ddagger \ddagger$ Traité de l'Electricité, iv. 264.

147

8s7, tom. xil. 163. [see Lond. and Edinb. Pliil. Mag., vol. xii. p. 196.]

IIII Phil. Trans., 1775, p. 94.

IT lbid. 1775 , p. 102.

"1** Personal Narrative, chap. $x$ vii. $\quad+\dagger \dagger$ Swedish Transactions, 1801, pp. 122. 156. $\$ \neq$ De Gymoto Electrico. Tubingen, 1819 .

|l III Bibliothèque Universelle, 1837, xii. p. 174. 
360 Dr. Faraday's Experimental Researches in Electricity, xv.

common in the Llanos de Caracas (near Calabozo), in all the small rivers which flow into the Orinoco, in English, French or Dutch Guiana, is not of difficult transportation. We lost them so soon at Paris because they were too much fatigued (by experiments) immediately after their arrival. MM. Norderling and Fahlberg retained them alive at Paris above four months. I would advise that they be transported from Surinam (from Essequibo, Demerara, Cayenne) in summer, for the Gymnotus in its native country lives in water of $25^{\circ}$ centigrade (or $77^{\circ}$ Fahr.). Some are five feet in length, but I would advise that such as are about twenty-seven or twentyeight inches in length be chosen. Their power varies with their food, and their state of rest. Having but a small stomach they eat little and often, their food being cooked meat, not salted, small fish, or even bread. Trial should be made of their strength and the fit kind of nourishment before they are shipped, and those fish only selected already accustomed to their prison. I retained them in a box or trough about four feet long, and sixteen inches wide and deep. The water must be fresh, and be changed every three or four days: the fish must not be prevented from coming to the surface, for they like to swallow air. A net should be put over and round the trough, for the Gymnotus often springs out of the water. These are all the directions that I can give you. It is, however, important that the animal should not be tormented or fatigued, for it becomes exhausted by frequent electric explosions, Several Gymnoti may be retained in the same trough."

1754. A Gymnotus has lately been brought to this country by Mr. Porter, and purchased by the proprietors of the Gallery in Adelaide Street; they immediately most liberally offered me the liberty of experimenting with the fish for scientific purposes; they placed it for the time exclusively at my disposal, that (in accordance with Humbeldt's directions (1753.)) its powers might not be impaired; only desiring me to have a regard for its life and health. I was not slow to take advantage of their wish to forward the interests of science, and with many thanks accepted their offer. With this Gymnotus, having the kind assistance of Mr. Bradley of the Gallery, Mr. Gassiot, and occasionally other gentlemen, as Professors Daniell, $Q$ wen, and Wheatstone, I have obtained every proof of the identity of its power with common electricity (265. 351, \&c.). All of these had been obtained before with the Torpedo (1750.), and some, as the shock, circuit, and spark (1751.), with the Gymnotus; but still I think a brief account of the results will be acceptable to the Royal So- 
ciety, and I give them as necessary preliminary experiments to the investigations which we may hope to institute when the expected supply of animals arrives (1752.).

1755. The fish is forty inches long. It was caught about March 1838; was brought to the Gallery on the 15th of August, but did not feed from the time of its capture up to the 19th of October. From the 24th of August Mr. Bradley nightly put some blood into the water, which was changed for fresh water next morning, and in this way the animal perhaps obtained some nourishment. On the 19th of October it killed and eat four small fish; since then the blood has been discontinued, and the animal has been improving ever since, consuming upon an average one fish daily:

1756. I first experimented with it on the 3rd of September, when it was apparently languid, but gave strong shocks when the hands were favourably disposed on the body $(1760.1773$, $\& \mathrm{c}$.). The experiments were made on four different days, allowing periods of rest from a month to a week between each. His health seemed to improve continually, and it was during this period, between the third and fourth days of experiment, that he began to eat.

1757. Beside the hands two kinds of collectors were used. The one sort consisted each of a copper rod fifteen inches long, having a copper disc one inch and a half in diameter brazed to one extremity, and a copper cylinder to serve as a handle, with large contact to the hand, fixed to the other, the rod from the disc upwards being well covered with a thick caoutchouc tube to insulate that part from the water. By these the states of particular parts of the fish whilst in the water could be ascertained.

1758. The other kind of collectors were intended to meet the difficulty presented by the complete immersion of the fish in water; for even when obtaining the spark itself I did not think myself justified in asking for the removal of the animal into air. A plate of copper eight inches long by two inches and a half wide, was bent into a saddle shape, that it might pass over the fish, and inclose a certain extent of the back and sides, and a thick copper wire was brazed to it, to convey the electric force to the experimental apparatus; a jacket of sheet caoutchouc was put over the saddle, the edges projecting at the bottom and the ends; the ends were made to converge so as to fit in some degree the body of the fish, and the bottom edges were made to spring against any horizontal surface on which the saddles were placed. The part of the wire liable to be in the water was covered with caoutchouc.

* The fish eaten were gudgeons, carp, and perch. 
1759. These conductors being put over the fish, collected power sufficient to produce many electric effects; but when, as in obtaining the spark, every possible advantage was needful, then glass plates were placed at the bottom of the water, and the fish being over them, the conductors were put over it until the lower caoutchouc edges rested on the glass, so that the part of the animal within the caoutchouc was thus almost as well insulated as if the Gymnotus had been in the air.

1760. Shock. The shock of this animal was very powerful when the hands were placed in a favourable position, i. e. one on the body near the head, and the other near the tail; the nearer the hands were togetber within certain limits the less powerful was the shock. The disc conductors (1757.) conveyed the shock very well when the hands were wetted and applied in close contact with the cylindrical handles; but scarcely at all if the handles were held in the dry hands in an ordinary way.

1761. Galvanometer. Using the saddle conductors (1758.) applied to the anterior and posterior parts of the Gymnotus, a galvanometer was readily affected. It was not particularly delicate; for zinc and platina plates on the upper and lower surface of the tongue did not cause a permanent deflection of more than $25^{\circ}$; yet when the fish gave a powerful discharge the deflection was as much as $30^{\circ}$, and in one case even $40^{\circ}$. 'The deflection was constantly in a given direction, the electric current being always from the anterior parts of the animal through the galvanometer wire to the posterior parts. The former were therefore for the time externally positive, and the latter negative.

1762. Making a magnet. When a little helix containing twenty-two feet of silked wire wound on a quill was put into the circuit, and an annealed steel needle placed in the helix, the needle became a magnet, and the direction of its polarity in every case indicated a current from the anterior to the posterior parts of the Gymnotus through the conductors used.

1763. Chemical decomposition. Polar decomposition of a solution of iodide of potassium was easily obtained. Three or four folds of paper moistened in the solution (322.) were placed between a platina plate and the end of a wire also of platina, these being respectively connected with the two saddle conductors (1758.). Whenever the wire was in conjunction with the conductor at the fore part of the Gymnotus, iodine appeared at its extremity; but when connected with the other conductor none was evolved at the place on the paper where it before appeared. So that here again the direction of the current proved to be the same as that given by the former tests. 
1764. By this test I compared the middle part of the fish with other portions before and behind it, and found that the conductor $A$, which being applied to the middle was negative to the conductor $B$ applied to the anterior parts, was, on the contrary, positive to it when $B$ was applied to places near the tail. So that within certain limits the condition of the fish externally at the time of the shock appears to be such, that any given part is negative to other parts anterior to it, and positive to such as are behind it.

1765. Evolution of heat. Using a Harris's thermo-electrometer belonging to Mr. Gassiot, we thought we were able in one case, namely, that when the deflection of the galvanometer was $40^{\circ}(1761$.), to observe a feeble elevation of temperature. I was not observing the instrument myself, and one of those who at first believed they saw the effect now doubts the result*.

1766. Spark. The electric spark was obtained thus. A good magneto-electric coil, with a core of soft iron wire, had one extremity made fast to the end of one of the saddle collectors (1758.), and the other fixed to a new steel file; another file was made fast to the end of the other collector. One person then rubbed the point of one of these files over the face of the other, whilst another person put the collectors over the fish, and endeavoured to excite it to action. By the friction of the files contact was made and broken very frequently; and the object was to catch the moment of the current through the wire and helix, and by breaking contact during the current to make the electricity sensible as a spark.

1767. The spark was obtained four times, and nearly all who were present saw it. That it was not due to the mere attrition of the two piles was shown by its not occurring when the files were rubbed together, independently of the animal. Since then I have substituted for the lower file a revolving steel plate, cut file-fashion on its. face, and for the upper file wires of iron, copper and silver, with all of which the spark was obtained $\psi$.

1768. Such were the general electric phænomena obtained from this Gymnotus whilst living and active in its native element. On several occasions many of them were obtained together; thus a magnet was made, the galvanometer de-

- In more recent experiments of the same kind we could not obtain the effect.

+ At a later meeting, at which attempts were made to cause the attraction of gold leaves, the spark was obtained directly between fixed surfaces, the inductive coil (1766.) being removed, and only short wires (by conparison) employed. 
flected, and perhaps a wire heated, by one single discharge of the electric force of the animal.

1769. I think a few further but brief details of experiments relating to the quantity and disposition of the electricity in and about this wonderful animal will not be out of place in this short account of its powers.

1770. When the shock is strong, it is like that of a large Leyden battery charged to a low degree, or that of a good voltaic battery of perhaps one hundred or more pairs of plates, of which the circuit is completed for a moment only. I endeavoured to form some idea of the quantity of electricity by connecting a large Leyden battery (291.) with two brass balls, above three inches in diameter, placed seven inches apart in a tub of water, so that they might represent the parts of the Gymnotus to which the collectors had been applied; but to lower the intensity of the discharge, eight inches in length of six-fold thick wetted string were interposed elsewhere in the circuit, this being found necessary to prevent the easy occurrence of the spark at the ends of the collectors (1758.), when they were applied in the water near to the balls, as they had been before to the fish. Being thus arranged, when the battery was strongly charged and discharged, and the hands put into the water near the balls, a shock was felt, much resembling that from the fish; and though the experiments have no pretension to accuracy, yet as the tension could be in some degree imitated by reference to the more or less ready production of a spark, and after that the shock be used to indicate whether the quantity was about the same, I think we may conclude that a single medium discharge of the fish is at least equal to the electricity of a Leyden battery of fifteen jars, containing 3500 square inches of glass coated on both sides, charged to its highest degree (291.). This conclusion respecting the great quantity of electricity in a single Gymnotus shock, is in perfect accordance with the degree of deflection which it can produce in a galvanometer needle (367. 860. 1761.), and also with the amount of chemical decomposition produced (374.860. 1763.) in the electrolyzing experiments.

1771. Great as is the force in a single discharge, the Gymnotus, as Humboldt describes, and as I have frequently experienced, gives a double and even a triple shock; and this capability of immediately repeating the effect with scarcely a sensible interval of time, is very important in the considerations which must arise hereafter respecting the origin and excitement of the power in the animal. Walsh, Humboldt, Gay-Lussac, and Matteucci have remarked the same thing of the Torpedo, but in a far more striking degree. 
1772. As, at the moment when the fish wills the shock, the anterior parts are positive and the posterior parts negative, it may be concluded that there is a current from the former to the latter through every part of the water which surrounds the animal, to a considerable distance from its body. The shock which is felt, therefore, when the hands are in the most favourable position, is the effect of a very small portion only of the electricity which the animal discharges at the moment, by far the largest portion passing through the surrounding water. This enormous external current must be accompanied by some effect within the fish equivalent to a current, the direction of which is from the tail towards the head, and equal to the sum of all these external forces. Whether the process of evolving or exciting the electricity within the fish includes the production of this internal current (which need not of necessity be as quick and momentary as the external one), we cannot at present say; but at the time of the shock the animal does not apparently feel the electric sensation which he causes in those around him.

1773. By the help of the accompanying diagram I will state a few experimental results which illustrate the current around the fish, and show the cause of the difference in character of the shock occasioned by the various ways in which the person is connected with the animal, or his position altered with respect to it. The large circle represents the tub in which the animal is confined; its diameter is forty-six inches, and the depth of water in it three inches and a half; it is supported on dry wooden legs. The figures represent the places where the hands or the disc conductors (1757.) were applied, and where they are close to the figure of the animal, it implies that contact with the fish was made. I will designate different persons by $\mathrm{A}, \mathrm{B}, \mathrm{C}, \mathrm{\&}$., $\mathrm{A}$ being the person who excited the fish to action.

1774. When one hand was in the water the shock was felt in that hand only, whatever part of the fish it was applied to ; it was not very strong, and was only in the part immersed in the water. When the hand and part of the arm was in, the shock was felt in all the parts immersed.

1775. When both hands were in the water at the same part of the fish, still the shock was comparatively weak, and only in the parts immersed. If the hands were on opposite sides, as at 1,2 , or at 3,4 , or 5,6 , or if one was above and the other below at the same part, the effect was the same. When the disc collectors were used in these positions no effect was felt by the person holding them, (and this corresponds with - the ubservation of Gay-Lussac on Torpedos*,) whilst other

* Annales de Chimie, xiv. p. 18. 
366 Dr. Faraday's Experimental Researches in Electricity, xv. persons, with both hands in at a distance from the fish, felt considerable shocks.

1776. When both hands or the disc collectors were applied at places separated by a part of the length of the animal, as at 1,3 , or 4,6 , or 3,6 , then strong shocks extending up the arms, and even to the breast of the experimenter, occur-

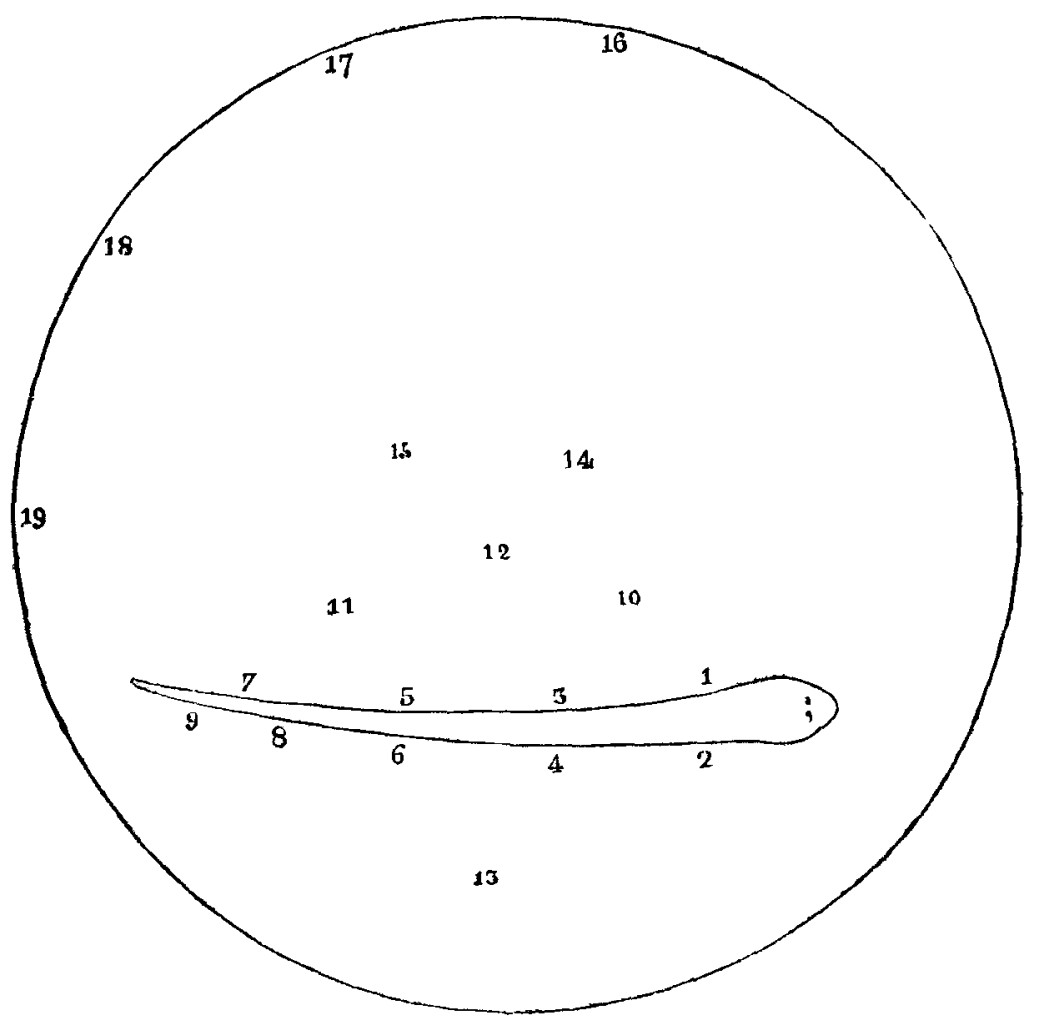

red, though another person with a single hand in at any of these places, felt comparatively little. The shock could be obtained at parts very near the tail, as at 8,9 . I think it was strongest at about 1 and 8 . As the hands were brought nearer together the effect diminished, until being in the same cross plane, it was, as before described, only sensible in the parts immersed (1775.)

1777. B placed his hands at 10,11, at least four inches from the fish, whilst $A$ touched the animal with a glass rod to excite it to action; B quickly received a powerful shock. In another experiment of a similar kind, as respects the non- 
necessity of touching the fish, several persons received shocks independently of each other; thus $A$ was at 4,6 ; B at 10, $11 ; C$ at 16,17 ; and $D$ at 18,19 ; all were shocked at once, $A$ and $B$ very strongly, $C$ and $D$ feebly. It is very useful whilst experimenting with the galvanometer or other instrumental arrangements, for one person to keep his hands in the water at a moderate distance from the animal, that he may know and give information when a discharge has taken place.

1778. When $B$ had both hands at 10,11 , or at 14, 15, whilst $A$ had but one hand at 1 , or 3 , or 6 , the former felt a strong shock, whilst the latter had but a weak one, though in contact with the fish. Or if $\mathrm{A}$ had both hands in at 1,2 , or 3,4 , or 5,6 , the effect was the same.

1779. If $A$ had the hands at 3,5, B at 14, 15, and $C$ at 16, 17, A received the most powerful shock, $B$ the next powerful, and $\mathbf{C}$ the feeblest.

1780. When $A$ excited the gymnotus by his hands at 8,9 , whilst $B$ was at 10,11 , the latter had a much stronger shock than the former, though the former touched and excited the animal.

1781. A excited the fish by one hand at 3 , whilst $B$ had both hands at 10,11, (or along), and $\mathrm{C}$ had the hands at 12, 13 (or across); A had the pricking shock in the immersed hand only (1774.); B had a strong shock up the arms; C felt but a slight effect in the immersed parts.

1782. The experiments I have just described are of such a nature as to require many repetitions before the general results drawn from them can be considered as established; nor do I pretend to say that they are anything more than indications of the direction of the force. It is not at all impossible that the fish may have the power of throwing each of its four electric organs separately into action, and so to a certain degree direct the shock, $i$. e. he may have the capability of causing the electric current to emanate from one side, and at the same time bring the other side of his body into such a condition, that it shall be as a non-conductor in that direction. But I think the appearances and results are such as to forbid the supposition, that he has any control over the direction of the currents after they have entered the fluid and substances around him.

1783. The statements also have reference to the fish when in a straight form; if it assume a bent shape, then the lines of force around it vary in their intensity in a manner that may be anticipated theoretically. Thus if the hands were applied at 1, 7, a feebler shock in the arms would be expected if the animul were curved with that side inwards, than if it were straight, because the distance between the parts 
368 Dr. Faraday's Experimental Researches in Electricity, xv.

would be diminished, and the intervening water therefore conduct more of the force. But with respect to the parts immersed, or to animals, as fish in the water between 1 and 7 , they would be more powerfully, instead of less powerfully, shocked.

1784. It is evident from all the experiments, as well as from simple considerations, that all the water and all the conducting matter around the fish through which a discharge circuit can in any way be completed, is filled at the moment with circulating electric power ; and this state might be easily represented generally in a diagram by drawing the lines of inductive action (1231. 130\%. 1338.) upon it: in the case of a gymnotus, surrounded equally in all directions by water, these would resemble generally, in disposition, the magnetic curves of a magnet, having the same straight or curved shape as the animal, i. e. provided he, in such cases, employed, as may be expected, his four electric organs at once.

1785. This gymnotus can stun and kill fish which are in very various positions to its own body ; but on one day when I saw it eat, its action seemed to me to be peculiar. A live fish about five inches in length, caught not half a minute before, was dropped into the tub. The gymnotus instantly turned round in such a manner as to form a coil inclosing the fish, the latter representing a diameter across it; a shock passed, and there in an instant was the fish struck motionless, as if by lightning, in the midst of the waters, its side floating to the light. The gymnotus made a turn or two to look for its prey, which having found he bolted, and then went searching about for more. A second smaller fish was given him, which being hurt in the conveyance, showed but little signs of life, and this he swallowed at once, apparently without shocking it. The coiling of the gymnotus round its prey had, in this case, every appearance of being intentional on its part, to increase the force of the shock, and the action is evidently exceedingly well suited for that purpose (1783.), being in full accordance with the well-known laws of the discharge of currents in masses of conducting matter; and though the fish may not always put this artifice in practice, it is very probable he is aware of its advaniage, and may resort to it in cases of need.

1786. Living as this animal does in the midst of such a good conductor as water, the first thoughts are thoughts of surprise that it can sensibly electrify anything; but a little consideration soon makes one conscious of many points of great beauty, illustrating the wisdom of the whole arrange- 
ment. Thus the very conducting power which the water has; that which it gives to the moistened skin of the fish or animal to be struck; the extent of surface by which the fish and the water conducting the charge to it are in contact; all conduce to favour and increase the shock upon the doomed animal, and are in the most perfect contrast with the inefficient state of things which would exist if the gymnotus and the fish were surrounded by air; and at the same time that the power is one of low intensity, so that a dry skin wards it off, though a moist one conducts it (1760.): so', is it one of great quantity (1770.), that though the surrounding water does conduct away much, enough to produce a full effect may take its course through the body of the fish that is to be caught for food, or the enemy that is to be conquered.

1787. Another remarkable result of the relation of the gymnotus and its prey to the medium around them is, that the larger the fish to be killed or stunned, the greater will be the shock to which it is subject, though the gymnotus may exert only an equal power; for the large fish has passing through its body those currents of electricity, which, in the case of a smaller one, would have been conveyed harmless by the water at its sides.

1788. The gymnotus appears to be sensible when he has shocked an animal, being made conscious of it, probably, by the mechanical impulse he receives, caused by the spasms into which it is thrown. When I touched him with my hands, he gave me shock after shock; but when I touched him with glass rods, or the insulated conductors, he gave one or two shocks, felt by others having their hands in at a distance, but then ceased to exert the influence, as if made aware it had not the desired effect. Again, when he has been touched with the conductors several times, for experiments on the galvanometer or other apparaturs, and appears to be languid or indifferent, and not willing to give shocks, yet being touched by the hands, they, by convulsive motion, have informed him that a sensitive thing was present, and he has quickly shown his power and his willingness to astonish the experimenter.

1789. It has been remarked by Geoffroy St. Hilaire, that the electric organs of the Torpedo, Gymnotus, and similar fishes, cannot be considered as essentially connected with those which are of high and direct importance to the life of the animal, but to belong rather to the common teguments; and it has also been found that such Torpedos as have been deprived of the use of their peculiar organs, have continued the functions of life quite as well as those in which Phil. Mag. S. 3. Vol. 15. No. 97. Nov. 1839. 2 B 
370 Dr. Faraday's Experimental Researches in Electricity, xv.

they were allowed to remain. These, with other considerations, lead me to look at these parts with a hope that they may upon close investigation prove to be a species of natural apparatus, by means of which we may apply the principles of action and re-action in the investigation of the nature of the nervous influence.

1790. The anatomical relation of the nervous system to the electric organ; the evident exhaustion of the nervous energy during the production of electricity in that organ; the apparently equivalent production of electricity in proportion to the quantity of nervous force consumed; the constant direction of the current produced, with its relation to what we may believe to be an equally constant direction of the nervous energy thrown into action at the same time; all induce me to believe, that it is not impossible but that, on passing electricity per force through the organ, a reaction back upon the nervous system belonging to it might take place, and that a restoration, to a greater or smaller degree, of that which the animal expends in the act of exciting a current, might perhaps be effected. We have the analogy in relation to heat and magnetism. Seebeck taught us how to commute heat into electricity; and Peltier has more lately given us the strict converse of this, and shown us how to convert the electricity into heat, including both its relation of hot and cold. Oersted showed how we were to convert electric into magnetic forces, and I had the delight of adding the other member of the full relation, by reacting back again and converting magnetic into electric forces. So perhaps in these organs, where nature has provided the apparatus by means of which the animal can exert and convert nervous into electric force, we may be able, possessing in that point of view a power far beyond that of the fish itself, to re-convert the electric into the nervous force.

1791. This may seem to some a very wild notion, as assuming that the nervous power is in some degree analogous to such powers as heat, electricity, and magnetism. I am only assuming it, however, as a reason for making certain experiments, which, according as they give positive or negative results, will regulate further expectation. And with respect to the nature of nervous power, that exertion of it which, is conveyed along the nerves to the various organs which they excite into action, is not the direct principle of life; and therefore I see no natural reason why we should not be allowed in certain cases to determine as well as observe its course. Many philosophers think the power is electricity. Priestley put forth this view in 1774 in a very striking and distinct form, both as regards ordinary animals and those 
which are electric, like the Torpedo*. Dr. Wilson Philip considers that the agent in certain nerves is electricity modified by vital action + . Matteucci thinks that the nervous fluid or energy, in the nerves belonging to the electric organ at least, is electricity $\ddagger$. MM. Prevost and Dumas are of opinion that electricity moves in the nerves belonging to the muscles; and M. Prevost adduces a beautiful experiment, in which steel was magnetized, in proof of this view; which, if it should be confirmed by further observation, and by other philosophers, is of the utmost consequence to the progress of this high branch of knowledge§. Now though I am not as yet convinced by the facts that the nervous fluid is only electricity, still $I$ think that the agent in the nervous system may be an inorganic force; and if there be reasons for supposing that magnetism is a higher relation of force than electricity (1664. 1731. 1734.), so it may well be imagined, that the nervous power may be of a still more exalted character, and yet within the reach of experiment.

1792. The kind of experiment I am bold enough to suggest is as follows. If a Gymnotus or Torpedo has been fatigued by frequent exertion of the electric organs, would the sending of currents of similar force to those he emits, or of other degrees of force, either continuously or intermittingly in the same direction as those he sends forth, restore him his powers and strength more rapidly than if he were left to his natural repose?

1793. Would sending currents through in the contrary direction exhaust the animal rapidly? There is, I think, reason to believe that the Torpedo (and perhaps the Gymnotus) is not much disturbed or excited by electric currents sent only through the electric organ; so that these experiments do not appear very difficult to make.

1794. The disposition of the organs in the Torpedo suggest still further experiments on the same principle. Thus when a current is sent in the natural direction, i. e. from below upwards through the organ on one side of the fish, will it

* Priestley on Air, vol. i. p. 277. Edition of 1774.

$\uparrow$ Dr. Wilson Philip is of opinion, that the nerves which excite the museles and effect the chemical changes of the vital functions, operate by the electric power supplied by the brain and spinal marrow, in its effects, modified by the vital powers of the living animal; because he found, as he informs me, as early as 1815 , that while the vital powers remain, all these functions can be as well performed by voltaic electricity after the removal of the nervous influence, as by that influence itself; and in the end of that year he presented a paper to the Royal Society, which was read at one of their meetings, giving an account of the experiments on which this position was founded.

I Bibliothèque Universelle, 1837, tom. xii. 192.

Ibid., 1887, xii. 202: xiv, 200 . 
excite the organ on the other side into action? or if sent through in the contrary direction, will it produce the same or any effect on that organ? Will it do so if the nerves proceeding to the organ or organs be tied? and will it do so after the animal has been so far exhausted by previous shocks as to be unable to throw the organ into action in any, or in a similar, degree of his own will?

1795. Such are some of the experiments which the conformation and relation of the electric organs of these fishes suggest, as being rational in their performance, and promising in anticipation. Others may not think of them as I do; but I can only say for myself, that were the means in my power, they are the very first that I would make.

Royal Institution, Nov. 9, 1838.

LV. Observations of Shooting Stars made on the Night of August 10, 1839. By EdW:Ard Cooper, Esq.

To the Editors of the Philosophical Magazine and Journal. Gentlemen, Birmingham, Aug. 31, 1839.

YOUR insertion of my letter to Dr. Robinson last year, in 1 the London and Edinburgh Philosophical Magazine, giving an account of observations on shooting stars made on the 10th of August at Geneva, induces me to trouble you with the present communication.

I was stationed at Brandsbury House, about three miles N.W. of London, on the night of the last 10th of August, and was assisted in my observations by two friends of mine, Messrs. Jones and Fenton. We confined our range to the Via Lactea, and expanse of sky to the north of it, as I had requested Sir James South, and the Messrs. Gwielt of London, to direct their attention to the south. During the preceding day the wind was pretty fresh from the S.W. and S.S.W. with flying clouds. An almost perfect lull of wind and a clear sky succeeded at about $7^{\mathrm{h}}$, and continued till about $11^{\mathrm{h}} 45^{\mathrm{m}}$. At about $12^{\mathrm{h}} 30^{\mathrm{m}}$ it was cloudy towards the N.W., and $2^{\mathrm{m}}$ or $3^{\mathrm{m}}$ later also towards N.E. . At $12^{\mathrm{h}} 50^{\mathrm{m}}$ all was again clear, and the stars appeared to be set on a perfectly black ground. These favourable circumstances continued until $13^{\mathrm{h}} 35^{\mathrm{m}}$, when the wind began to stir, and seemed northing a little, and several clouds of dark hue rose from the $N$. and N.E. horizon. These however partially passed away, but in $10^{\mathrm{m}}$ more the N.W. horizon showed symptoms of spreading a more formidable veil. This gradually extended itself, with occasional openings, over the entire heavens, till at $14^{\mathrm{h}} 15^{\mathrm{m}}$ all was shut out, and after waiting some time without any change 